\title{
Inductive Effects of Carbohydrates and Plant Regeneration via Anther Culture in Madagascar Periwinkle
}

\author{
Vivek R. Narkhedkar ${ }^{1, *}$, Jaykiran A. Tidke ${ }^{2}$ \\ ${ }^{1}$ M.J.F. Com., Sci. and V.R. Arts College, Bhatkuli, Amravati (M.S.), India \\ ${ }^{2}$ Laboratory of Reproductive Biology of Angiosperms, Department of Botany, Sant Gadge Baba Amravati University, Amravati (M.S.), \\ India
}

Received June 11, 2020; Revised October 23, 2020; Accepted November 3, 2020

\section{Cite This Paper in the following Citation Styles}

(a): [1] Vivek R. Narkhedkar, Jaykiran A. Tidke, "Inductive Effects of Carbohydrates and Plant Regeneration via Anther Culture in Madagascar Periwinkle," Advances in Zoology and Botany, Vol. 9, No. 3, pp. 65 - 70, 2021. DOI: 10.13189/azb.2021.090301.

(b): Vivek R. Narkhedkar, Jaykiran A. Tidke (2021). Inductive Effects of Carbohydrates and Plant Regeneration via Anther Culture in Madagascar Periwinkle. Advances in Zoology and Botany, 9(3), 65 - 70. DOI: 10.13189/azb.2021.090301.

Copyright $\mathrm{O} 2021$ by authors, all rights reserved. Authors agree that this article remains permanently open access under the terms of the Creative Commons Attribution License 4.0 International License

\begin{abstract}
Anther culture has emerged as an alternative for traditional plant breeding practices for homozygosity development, which in the case of medical plants resulting in increased yield of phytoconstituents. The response of anthers during culture is governed by the various constituents of the nutrient media. The carbohydrate in the nutrient media plays a pivotal role as it acts as a source of carbon skeleton and maintains the osmoticum. In the present research, anthers of Catharanthus roseus (L.) G. Don. at early to late uninucleate stage of development were selected for the experiment. The anthers were cultured to evaluate the androgenic potential under the influence of different types and concentrations of carbohydrates viz. sucrose, glucose, maltose, and galactose. It was found that out of four carbohydrates except maltose, all performed best at $30 \mathrm{gm} / \mathrm{l}$. The maximum rate of androgenic callus induction was noted in sucrose at $30 \mathrm{gm} / 1(69.66 \pm 1.52 \%)$. All the carbohydrates showed the least rate of calli induction at high concentration i.e. $70 \mathrm{gm} / \mathrm{l}$. The embryo like structures were able to develop on the media supplemented with the combination of $1 \mathrm{mg} / 1 \mathrm{BAP}, 0.5$ $\mathrm{mg} / \mathrm{l}$ Kinetin and $0.5 \mathrm{mg} / \mathrm{l}$ NAA $(13.33 \pm 5.77 \%)$. The ploidy analysis of randomly selected 30 calli and 10 leaves revealed that Catharanthus roseus has haploid regeneration tendencies and also possesses a tendency for spontaneous double haploid formation.
\end{abstract}

Keywords Sucrose, Haploids, Anther, Maltose, Catharanthus roseus, Carbohydrates

\section{Introduction}

The strong and growing demand in today's marketplace for natural, renewable products has refocused attention on in vitro plant materials as potential factories for secondary phytochemical production. Double Haploid (DH) technology is valuable in the breeding of medicinal plant species [1] and for generating resources to develop new varieties showing enhanced vigor and yield i.e. high levels of medicinal compounds [2]. In this context, raising in vitro haploids in Catharanthus roseus (L). G. Don. offers anticipated benefits which would have been remained unexpressed in natural heterozygous diploid population.

Anther culture is still restricted by many factors which govern the phenomenon of androgenesis. Among the many decisive factors, media constituents are some of the invincible factors which determine the success rate in androgenesis [3]. In vitro cultures of plant tissues including those which turn green when exposed to light are not autotrophic with respect to carbonaceous nutrition [4]. Cultures require an external source of organic carbon for 
energy and biosynthesis; the type and the concentration needed for the best possible growth vary with different cultures [5]. Thus, in nutrient media, sugar provides the carbon skeleton and energy and it also acts as an osmoticum in the induction medium. High concentration of the sucrose in the medium is responsible for maintaining osmotic pressure of the nutrient medium [6]. Gene expression induced by sugar plays an important role in the diversion of microspore from the gametophytic to the sporophytic pathway [7]. The higher applicability of sucrose as a carbon and energy source in in vitro culture is because sucrose is a disaccharide that has high solubility in water with a role as a molecule transporter. Sucrose can be easily penetrated through the plasma membrane $[8,9]$.

In $C$. roseus the reports available on in vitro cultures mainly focused on the plant regeneration through somatic tissues [10-12], some reported phytochemical production via callus culture $[13,14]$ and a very few studies are performed on androgenesis [15-18]. Since the reports of androgenesis success in Catharanthus roseus have been limited and also lacking the experiments on the factors influencing the androgenesis, this study is undertaken to investigate the potential of various carbon sources to act as an efficient energy source and optimal osmoticum.

\section{Materials and Methods}

\subsection{Plant Material}

The Catharanthus roseus plants were raised in the pots in the greenhouse at the Departmental botanical garden. The plants were grown at $27^{\circ} \mathrm{C}$ and $65 \%$ humidity without the application of any fertilizers and pesticides. The explant donor plants were selected on the basis of floral buds having microspores at the early to late uninucleate stage of development (Figure 1 and 2). The developmental stages of microspores inside the anthers were determined by $1 \%$ acetocarmine staining. The floral buds (Figure 1 ) and the microspore developmental stages (Figure 2) belong to the same plant.

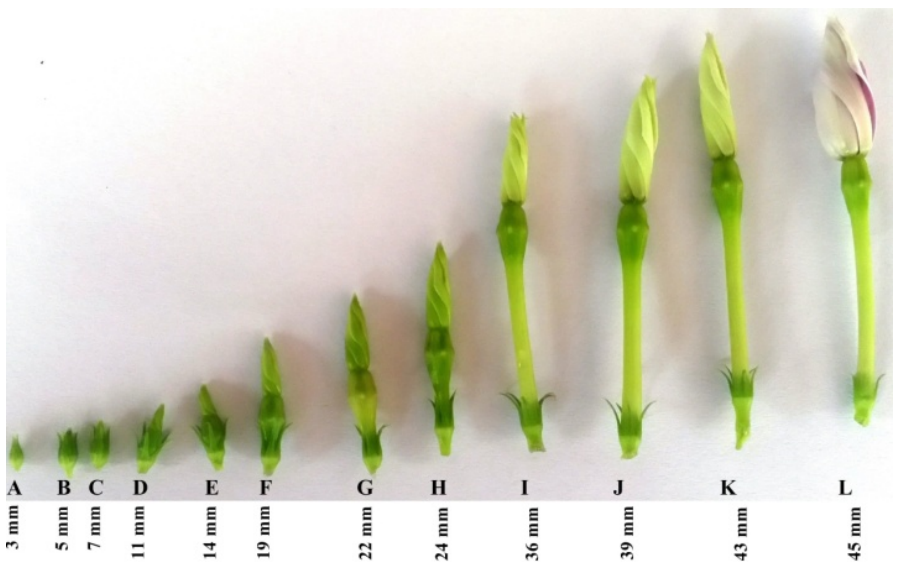

(A: Meiotic bud; B: Pollen tetrad stage; C to F: Uninucleate stage; $\mathbf{G}$ to L: Mature pollen)

Figure 1. (A-L): Morphological variations in floral buds with respect to the microspore developmental stages

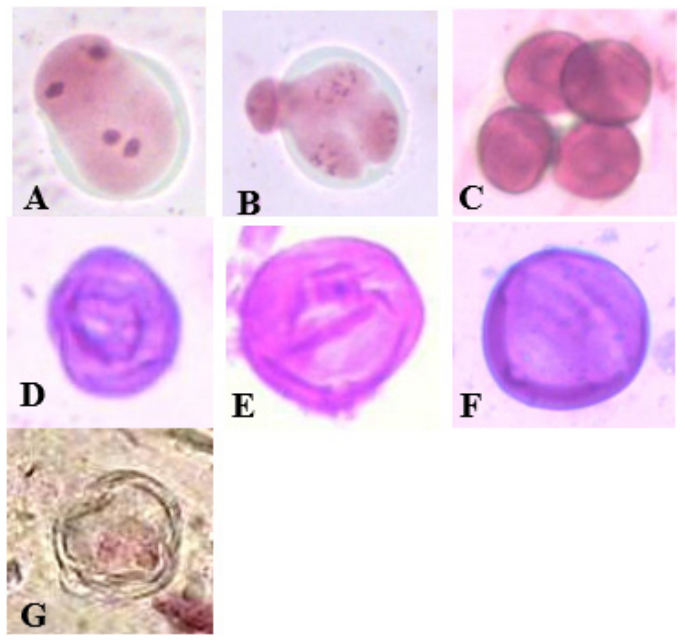

(A to B: Meiotic bud; C: Pollen tetrad stage; D to F: Uninucleate stage; G: Mature pollen)

Figure 2. (A-G): Variations in microspore developmental stages in floral buds of Catharanthus roseus 


\subsection{Explant Preparation}

The floral buds having anthers at early to late uninucleate stage of development were subjected to optimal cold pretreatment at $8^{\circ} \mathrm{C}$ for 10 days [19]. The pretreated floral buds were surface sterilized in $1 \%$ labogent, $0.1 \%$ mercuric chloride and $50 \%$ ethanol for 5 minutes, 2 minutes and 2 minutes respectively, followed by two successive wash by distilled water for 2 minutes each.

\subsection{Anther Culture}

The pretreated anthers were excised from surface sterilized floral buds. Anthers were cultured in agar solidified MS media having variables as different types and concentrations of carbon source i.e. sucrose, glucose, maltose, and galactose at $30 \mathrm{gm} / 1,50 \mathrm{gm} / 1$ and $70 \mathrm{gm} / 1$. A constant pre-optimized growth regulators combination i.e. $7 \mathrm{mg} / 1$ 2,4-D, NAA $0.5 \mathrm{mg} / \mathrm{l}$ and BAP $1.5 \mathrm{mg} / 1$ was utilized for calli induction [20]. In every experimental set, 100 anthers were inoculated to evaluate the rate of androgenic callus induction. Culture conditions were maintained at $25 \pm 1{ }^{\circ} \mathrm{C}$ temperature, $50-60 \%$ relative humidity and complete 24 hours dark period. Control set without carbohydrate was also run.

The Embryo Like Structures (ELS) developed on induced callus were maintained on Himedia's MS media PT100 supplemented with ABA $0.01 \mathrm{mg} / 1, \mathrm{GA}_{3} 5.0 \mathrm{mg} / \mathrm{l}$, and myo-inositol $100 \mathrm{mg} / \mathrm{l}$ for 10 days under 16 hours light period. Later, such ELS were cultured on MS media supplemented with BAP, Kinetin (KIN) and NAA. Culture conditions were maintained at $25 \pm 1^{\circ} \mathrm{C}$ temperature, $50-60 \%$ relative humidity and 16 hours light period. Control set without growth regulators was also run. All the experiments were repeated three times.

\subsection{Ploidy Analysis}

The ploidy status of induced callus and leaves from plant regenerated was analyzed. The selection done was random; 30 callus samples and 10 leaves were examined by Applied Biosystems attune acoustic focusing flow cytometer.

\subsection{Data Analysis}

All experiments were repeated thrice and the data obtained were subjected to ANOVA at $95 \%$ confidence interval through Graphpad Prism version 6.

\section{Results}

\subsection{Inductive Effects of Carbohydrates}

The obtained results for the callus induction experiments confirmed the influential inductive effect of studied carbohydrates. The derived data subjected to two-way ANOVA with Dunnett's multiple comparison test with control showed that all the means were significant at $\mathrm{P}<0.05$ for calli induction.

The first response in callus induction was noted after 21 days in glucose at $50 \mathrm{gm} / \mathrm{l}$. An indirect androgenesis was observed as the anther culture responded by forming callus via repeated divisions of microspore. The maximum percentage of callus induction was found in sucrose at 30 $\mathrm{gm} / 1$ at i.e. $69.66 \pm 1.52 \%$ (Figure $3 \mathrm{~A}$, Figure 4 ) and least was observed in galactose at $70 \mathrm{gm} / 1$ i.e. $40.33 \pm 4.16 \%$ (Figure 4). The time required to respond in maximum and minimum callus inducing concentration was 25 and 28 days respectively.
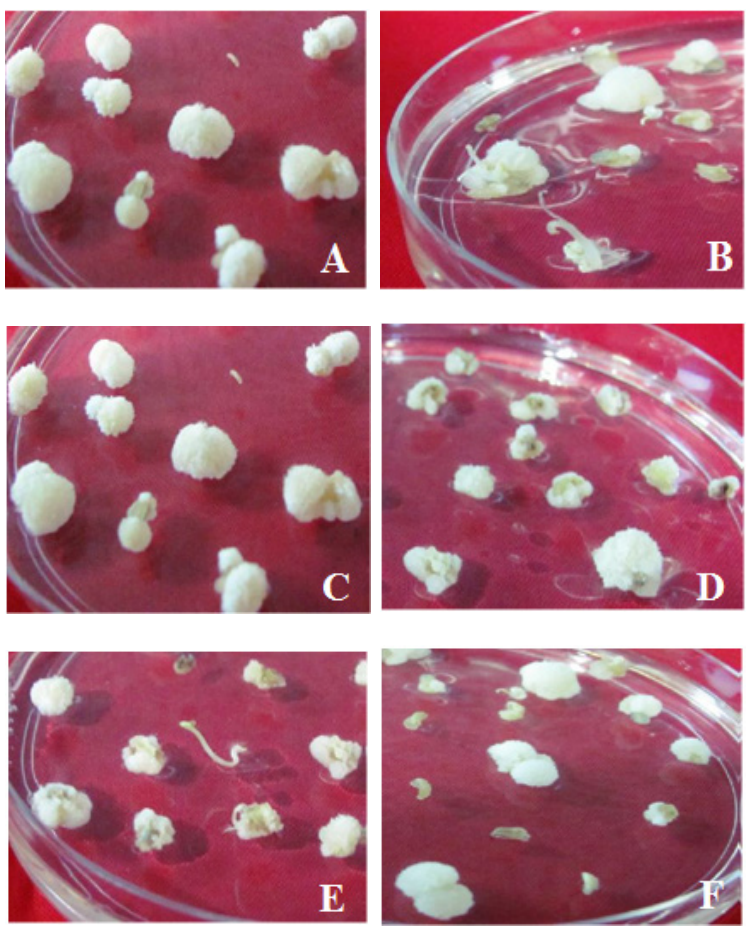

(A: 30 gm/1 Sucrose; B: 30 gm/1 Maltose; C: 50 gm/1 Sucrose; D: 50 gm/1 Maltose; E: 30gm/1 Glucose; F: $30 \mathrm{gm} / 1$ Galactose)

Figure 3. (A-F): A variable response in androgenic callus induction in Catharanthus roseus (L.) G. Don. in different types and concentrations of carbohydrates

In the performed experiment, all four carbohydrates showed inhibition in callus induction at high concentration i.e. $70 \mathrm{mg} / 1$ (Figure 4). Except for maltose at $50 \mathrm{gm} / 1$ (Figure $3 \mathrm{D}$, Figure 4), all three carbohydrates performed well at $30 \mathrm{gm} / 1$ concentration as compared to other two concentrations (Figure $3 \mathrm{~A}, \mathrm{E}, \mathrm{F}$ and Figure 4). At high induction rate among all four carbohydrates order of influence is sucrose $>$ maltose $>$ glucose $>$ galactose. With an increase in the concentration of each source, although there is a difference among induction efficiency at each level but no significant notable differences were observed in all carbohydrate sources except maltose (Figure $3 \mathrm{~A}-\mathrm{F}$ and Figure 4). All the carbohydrates showed the decreased 
rate of calli induction with increasing concentration of carbohydrate source from $30 \mathrm{gm} / 1,50 \mathrm{gm} / 1$, and $70 \mathrm{gm} / 1$, except maltose. In maltose, rate of influence was $50 \mathrm{gm} / 1>$ $30 \mathrm{gm} / 1>70 \mathrm{gm} / 1$.

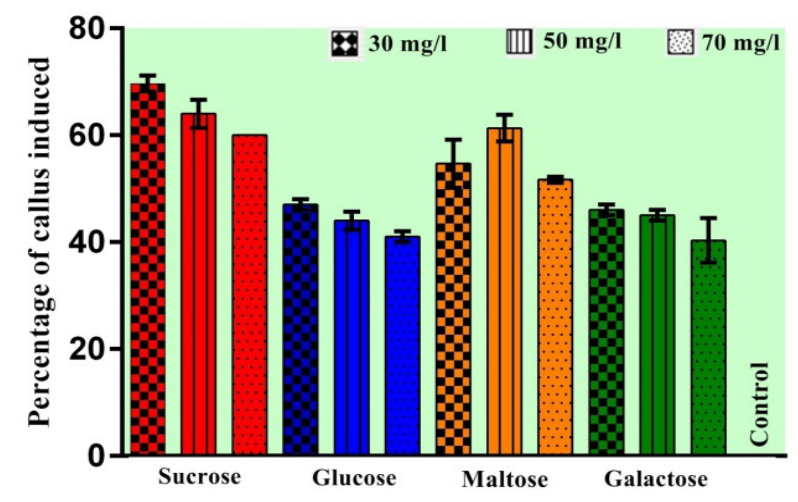

Carbohydrate source

The experiment was repeated three times and two-way ANOVA with Dunnett's multiple comparison test with control showed that all mean were significant at $\mathrm{P}<0.05$ for calli induction

Figure 4. Percentage of calli induction in various types and concentrations of carbohydrates in anther culture of Catharanthus roseus (L.) G. Don

\subsection{Plant Regeneration via Embryo Like Structures}

All experimental sets resulted in the formation of calli which sometimes bears the embryo like structures. Such developed ELS were utilized for plant regeneration. The developed ELS were incubated for maintenance of viability and vigor and then cultured on twelve combinations of plant growth regulators along with one control set.

The obtained results showed an inadequate response in plant regeneration and instability of culture, as the plantlets developed could not reach the maturity. In the observations for plant regeneration, the shoot induction/initiation assumed to be differing from plant regeneration. The shoot induction means the stage when ELS show bifurcation or development of green coloration at the apical position. Whereas, shoot regeneration means conversion of bifurcation or developed green coloration into the green leaf like structures.

The first response was noted after 40 days in $1.5 \mathrm{mg} / \mathrm{l}$ BAP. Out of thirteen sets, only eight combinations showed shoot induction by forming bifurcation at the apical tip. But out of those, only two combinations i.e. BAP, Kinetin and $\mathrm{NAA}$ at $0.5 \mathrm{mg} / 1,1.0 \mathrm{mg} / \mathrm{l}$ and $0.5 \mathrm{mg} / \mathrm{l}$ respectively along with BAP, Kinetin and NAA at $1.0 \mathrm{mg} / \mathrm{l}, 0.5 \mathrm{mg} / \mathrm{l}$ and 0.5 $\mathrm{mg} / \mathrm{l}$ respectively were found to be beneficial for plantlets formation (Figure $5 \mathrm{~A}, \mathrm{~B}$ ). These regenerated plantlets were able to attain a maximum of $3.0 \pm 0.2 \mathrm{~cm}$ shoot length. Establishment of prolonged culture was not possible. Among all twelve combinations, seven sets were responded by shoot initiation but the rate of initiation was found to be low. The best induction and best regeneration response were noted in the same combination i.e. BAP, Kinetin, and NAA at $1.0 \mathrm{mg} / 1,0.5 \mathrm{mg} / 1$ and $0.5 \mathrm{mg} / \mathrm{l}$ respectively.
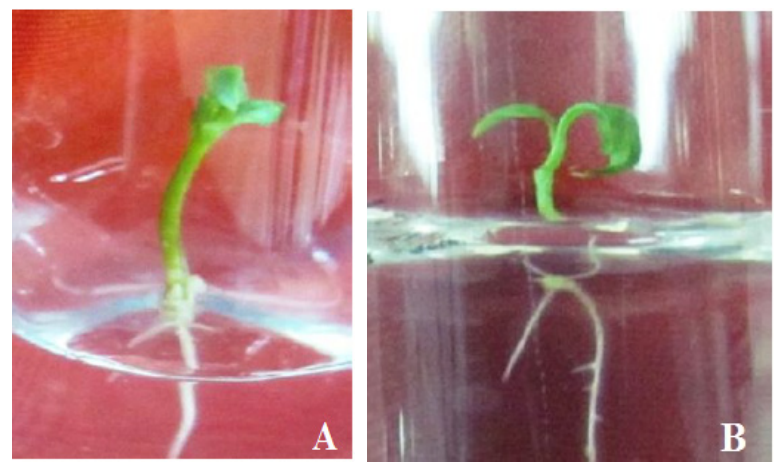

(A: BAP $1.0 \mathrm{mg} / \mathrm{l}$, Kinetin $0.5 \mathrm{mg} / 1$ and NAA $0.5 \mathrm{mg} / 1$; B: BAP $0.5 \mathrm{mg} / \mathrm{l}$, Kinetin $1.0 \mathrm{mg} / \mathrm{l}$ and NAA $0.5 \mathrm{mg} / \mathrm{l}$ ).

Figure 5. (A-B) The response of ELS showing shoot regeneration in Catharanthus roseus(L.) G. Don. in MS media

\subsection{Ploidy Analysis}

The flow cytometry analysis of randomly selected thirty calli and ten leaves samples revealed $78 \%$ haploid callus, whereas diploids were $12.24 \%$ and aneuploids were $9.76 \%$. While out of ten randomly sampled leaflets of the plants regenerated from ELS, nine showed haploid status i.e. $99 \%$.

\section{Discussion}

Earlier reports on anther culture of Catharanthus roseus don't perform experiments to deduce the efficient carbon source [15-18].

The obtained dominance of sucrose over maltose in callus induction can be due to the fact that maltose is hydrolyzed 20 times slower than sucrose, so the absorption and metabolism of maltose as compared to sucrose required more time. Such effect of maltose leads to the decline in level of carbohydrates and consequently low available carbon skeleton and energy for growth and development. Also, the slow growth of callus under the influence of maltose was reported to be associated with the enhanced protein synthesis and decline in starch and hexose endogenous levels [21]. Like present report for maltose, in barley anther culture, a relatively high concentration of maltose i.e. $62 \mathrm{gm} / 1$ in the induction medium has been proven successful. Also, maltose could be used from $60 \mathrm{gm} / 1$ to $90 \mathrm{gm} / 1$ in anther culture of rye, rice, and wheat [22]. Studies on Petunia anther culture reported the inhibitory effect of fructose and glucose to pollen [23]. For Clementine anther culture, galactose at 9 $\mathrm{gm} / \mathrm{l}$ and lactose at $18 \mathrm{gm} / \mathrm{l}$ are frequently used [24]. Similar to present findings, sucrose was found to be the 
excellent carbohydrate source, compared to glucose in the anther culture of two mandarin cultivars and two Clementine [25]. In contrast to the present findings, glucose performed better than sucrose in rye culture [26].

Parallel to a current study, results noted by Mousa [27] revealed that in Broccoli (Brassica oleracea var italica), higher percentage of androgenic embryoids $(90 \%)$ was produced on MS medium with sucrose concentration (30 $\mathrm{gm} / \mathrm{l})$. Results obtained for the choice of carbon source in anther culture of Brassica oleracea L. for callus and shoot development are in accordance with the present study [28]. Ismaili and Mohammadi [29], reported maximum embryogenesis in YPm basal medium supplemented with $60 \mathrm{gm} / 1$ sucrose and the lowest rate was observed in medium with $60 \mathrm{gm} / 1$ maltose. High concentrations of sucrose or maltose were found to be essential for embryogenesis in anther culture of maize.

In the case of plant regeneration, Kim et al., [17] reported the low frequency of plant regeneration via embryogenesis in Catharanthus roseus. But all the developed plants were somatic in origin and diploids, no haploid regeneration was reported. Unlike this, Lee et al., [18] obtained efficient plant regeneration via embryogenesis in C. roseus but the ploidy analysis for knowing the somatic or gametic origin of regenerants was not reported. George, [16] obtained no embryogenesis and no plant regeneration in anther culture of $C$. roseus and reported only $5 \%$ response for calli production. Calli thus obtained was all reported to be diploid.

In contrast to the efficiency of the present report, Lantos et al., [30] reported an efficient anther culture protocol for spelt wheat. The number of ELS was produced 62.2 per 100 anthers. The culture of ELS regenerated 30.6 green plantlets per 100 cultured anthers. The rate of green plantlets generation was $89.0 \%$. Whereas, Kahrizi et al., [31] reported a low success rate of androgenesis is on Hordeum vulgare $\mathrm{L}$. The results obtained showed the effect of genotype on embryo induction and total plant regeneration. The best results for embryo production, green and total plant regeneration were reported to be $74.792 \%$, $7.293 \%$, and $17.29 \%$, respectively. This relation between high rates of embryoids induction with low rate of plant regeneration is also evident in the present report.

The obtained ploidy variation during culture is also affirmative with respect to the ploidy variation occurs during culture period in various genotypes. Along with haploids or DHs, non-haploids i.e. diploid, triploid, tetraploid, pentaploid, hexaploid, aneuploid have also been reported for various genotypes in anther culture studies [32].

\section{Conclusions}

In the studies on androgenesis in Catharanthus roseus (L.) G. Don. various conclusions were drawn from the experiments conducted. It was concluded that sucrose at 30 $\mathrm{gm} / \mathrm{l}$ was more beneficial than other three carbon sources, except in maltose. The ELS produced required incubation on media were designed for maintenance of vigor and viability. But still, a low regeneration rate was achieved with the combination of $1 \mathrm{mg} / 1 \mathrm{BAP}, 0.5 \mathrm{mg} / 1$ Kinetin and $0.5 \mathrm{mg} / 1 \mathrm{NAA}$. In the ploidy analysis, it is concluded that Catharanthus roseus showed haploid regeneration tendencies and also possessed the tendency for spontaneous double haploids production.

\section{Acknowledgements}

Authors gratefully acknowledge Dr. Kiran Kharat, Head, CFALS, Deogiri College, Aurangabad (M.S.), India for providing necessary facilities for flow cytometry analysis.

\section{REFERENCES}

[1] A. M. R., Ferrie. Current Status of Doubled Haploids in Medicinal Plants. In: Touraev A, Forster BP, Jain SM (Eds). Advances in Haploid Production in Higher Plants. Springer Netherlands, Dordrecht, pp. 209-217, 2009.

[2] A. M. R., Ferrie. Doubled haploid production in nutraceutical species: a review. Euphytica, Vol. 158, 347$357,2007$.

[3] S. M. Jain,S. K. Sopory and R. Veilleux R (Eds).In Vitro Haploid Production in Higher Plants: Volume 1: Fundamental Aspects and Methods, Current Plant Science and Biotechnology in Agriculture. Springer Netherlands, 1996.

[4] R. G. Butenko and M. K. Chailakian. Plant tissue culture and plant morphogenesis, Israel Program for Scientific Translations, Jerusalum, 1968

[5] A. H. G. Kumar and H. N. Murthy. Effect of sugars and amino acids on androgenesis of Cucumis sativus. Plant Cell Tissue and Organ culture, Vol.78, 201-208, 2004.

[6] R. S. Chaleff and A. Stolarz. Factors influencing the frequency of callus formation among cultured rice (Oryza sativa) anthers. PhysiolPlantarum, Vol.51, 201-206, 1981.

[7] S. Smeekens and F. Rook. Sugar sensing and sugar-mediated signal transduction in plants. PlantPhysiol, Vol.115, 7-13, 1997.

[8] P. Baskaran and N. Jayabalan. Role of basal media, carbon sources and growth regulators in micropropagation of Eclipta alba-a valuable medicinal herb. KMITL Science Journal, Vol. 5: 469-482, 2005.

[9] F. Javed and S. Ikram. Effect of sucrose induced osmotic stress on callus growth and biochemical aspects of two wheat genotypes. Pakistan Journal ofBotany, Vol. 40, 1487 $1495,2008$.

[10] H. S. Taha, M. K. El-Bahrand N. M. Seif-El-Nasr. In Vitro studies on Egyptian Catharanthus roseus (L.) G. Don. : Calli Production, Direct Shootlets Regeneration and Alkaloids 
Determination. Journal of Applied Science Research, Vol. 4, 1017-1022, 2008

[11] M. Faheem, S. Singh, B. S. Tanwer and M. Khan. In vitro Regeneration of multiplication shoots in Catharanthus roseus- An important medicinal plant. Advanced and Applied Science Research, Vol. 2, 2008-2013, 2011.

[12] J. Mehta, D. Upadhyay, P. Paras, R. Ansariand S. Tiwari. Multiple shoots regeneration of (anti-cancer plant) Catharanthus roseus - An important medicinal plant American Journal of PharmTech Research, Vol. 3, 785-793, 2013.

[13] A. Ataei-Azimi, B. D. Hashemloian, H. Ebrahimzadeh and A. Majd. High in vitro production of ant-canceric indole alkaloids from periwinkle (Catharanthus roseus) tissue culture. African Journal of Biotechnology, Vol. 7, 2834 2839, 2008.

[14] A. K. Verma, R. R. Singh and S. Singh. Improved alkaloid content in callus culture of Catharanthus roseus. BotanicaSerbica, Vol. 36, 123-130, 2012.

[15] A. A. Abou-Mandour, S. Fischer and F. C. Czygan. Regeneration of intact plants from haploid and diploid callus cells of Catharanthus roseus. Z Pflanzenphysiol, Vol. 91, 83-88, 1979

[16] L. George. Anther culture of Catharanthus roseus L.-Development of pollen embryoids. Curr Sci India, Vol. 54, 641-642, 1985.

[17] S. W. Kim, N. H. Song, K. H. Jung, S. S. Kwak and R. Liu. High frequency plant regeneration from anther-derived cell suspension cultures via somatic embryogenesis in Catharanthus roseus. Plant Cell Report, Vol. 13, 319-322, 1994.

[18] S. Y. Lee, H. J. Kang, P. S. Choi, J. R. Liu and H. J. Chung. Embryogenesis and plant regeneration from Vinca (Catharanthus roseus L.) anther culture. In: Proceedings of the Korean Society of Plant Biotechnologist. pp. 174, 2002.

[19] V. R. Narkhedkar, J .A. Tidke, N. J. Chikhale and S. N. Bhusari. Cold stress induced callogenesis from isolated anthers of Cathranthus roseus (L.) G. Don. International Journal of Pharma and Biosciences, Vol. 7, 40-45, 2016.

[20] V. R. Narkhedkar and J. A. Tidke. Analysis of various pretreatments and 2,4-D concentrations on callus induction and high efficiency of haploids regeneration in Catharanthus roseus (L.) G. Don. American Journalof PharmTech Research, Vol. 6, 246-256, 2016.

[21] G. Blanc, L. Lardet, A. Martin, J. L. Jacob and M. P. Carron. Differential carbohydrate metabolism conducts morphogenesis in embryogenic callus of Heveabrasiliensis
(Mull. Arg.). Journal of Experimental Botanny, Vol. 53, 1453-1462, 2002.

[22] M. Wedzony, B. P. Forster, I. Żur, E. Golemiec, M.Szechyńska-Hebda, E. Dubas, G. Gotębiowska andM. Wędzony. Progress in Doubled Haploid Technology in Higher Plants. In: Touraev A, Forster BP, Jain SM. (Eds). Advances in Haploid Production in Higher Plants. Springer Netherlands, Dordrecht, pp. 1-33, 2009.

[23] C. Raquin. Utilization of different sugars as carbon source for in vitro anther culture of Petunia. Z Pflanzenphysiol, Vol.111, 453-457, 1983.

[24] M. A. Germanà. Haploids and doubled haploids in Citrus spp. In: Maluszynski M, Kasha KJ, Forster BP, Szarejko I (Eds). Doubled Haploid Production in Crop Plants. Springer, Dordrecht, pp. 303-307, 2003.

[25] M. A. Germanà, Ying Wang, M. G. Barbagallo, G. Iannolino and F. G. Crescimanno. Recovery of haploid and diploid plantlets from anther culture of Citrus clementina Hort, ex Tan. and Citrus reticulata Blanco. Journal of Horticultural Science, Vol. 69, 473-480, 1994.

[26] G. Wenzel, F. Hoffmann and E. Thomas. Increased induction and chromosome doubling of androgenetic haploid rye.Theor Appl Genet, Vol. 51, 81-86, 1977.

[27] M. A. Mousa, A. G. Haridy,H. S. Abbas and M. F. Mohammed. Improved androgenesis of Broccoli (Brassica oleracea var italica) anthers using sucrose and growth regulators. Asian Journalof Crop Science, Vol. 6, 133-141, 2014.

[28] T. O. Cristea, C. Leonte, M. Prisecaru, C. Brezeanu and M. Brezeanu. Effect of carbohydrate source over the androgenesis of Brassica oleraceae L. anthers cultivated in vitro. Agro Ser Sci Res, Vol. 55: 169-172, 2012.

[29] A. Ismaili and P. P. Mohammadi. Effect of genotype, induction medium, carbohydrate source, and polyethylene glycol on embryogenesis in maize (Zea mays L.) anther culture. Acta Physiol Plant, Vol. 38, 74, 2016.

[30] C. Lantos, B. Jenes, L. Bóna, M. Cserháti and J. Pauk. High frequency of doubled haploid plant production in spelt wheat. Acta Biol Cracov Bot, Vol. 58, 107-112, 2016.

[31] D. Kahrizi, S. Mahmoodi, G. R. BakhshiKhaniki and M. Mirzaei. Effect of genotype on androgenesis in barley (Hordeum vulgare L.). Biharean Biol, Vol. 5, 132-134, 2011.

[32] J. M. Dunwell. Haploids in flowering plants: origins and exploitation. Plant Biotechnology Journal, Vol. 8, 377-424, 2011. 